\title{
Perspectives of College Students on HPV and Its Causation to Cancer: Are They Misinformed?
}

\author{
Richard C. McKinnies, Sandra K. Collins, Jennifer S. Sherry, Anthony Fleege, \\ Marcea Walter, Kyle Chamness \\ School of Allied Health, College of Applied Science and Arts, Southern Illinois University, Carbondale, IL, USA \\ Email:rmck@siu.edu
}

How to cite this paper: McKinnies, R.C., Collins, S.K., Sherry, J.S., Fleege, A., Walter, M. and Chamness, K. (2017) Perspectives of College Students on HPV and Its Causation to Cancer: Are They Misinformed? Advances in Breast Cancer Research, 6, 43 48.

https://doi.org/10.4236/abcr.2017.62004

Received: September 22, 2016

Accepted: March 31, 2017

Published: April 1, 2017

Copyright $\odot 2017$ by authors and Scientific Research Publishing Inc. This work is licensed under the Creative Commons Attribution International License (CC BY 4.0).

http://creativecommons.org/licenses/by/4.0/

\begin{abstract}
This study endeavors to look at the overall level of understanding of the $\mathrm{Hu}$ man Papillomavirus (HPV) among college-age students and whether or not they can deduct what types of cancer are directly correlated with the infection. The research will present the disparity in knowledge among the surveyed college students and how the majority of this age group knows very little about HPV's carcinogenic effects and how it could affect them later in life.
\end{abstract}

\section{Keywords}

HPV, HPV Causation to Cancer, HPV College Perspective, HPV Infection

\section{Introduction}

The Human Papillomavirus (HPV), which causes genital warts, has been described for centuries. However, it has been in just the past few decades (around the 1970's) that major breakthroughs have been made concerning HPV [1]. Since this time, over 100 different strands have been identified and it is estimated that over one third of these strands infect the genital track [2]. The Centers for Disease Control and Prevention [3] approximate that in 2014, 79 million Americans were infected with HPV and that about 14 million new people will be infected each year. The CDC also estimates at least $80 \%$ of women will acquire an HPV infection by the time they reach 50 years of age [4].

Warts can be a physical appearance that develops due to many strands of the HPV infection. However, a more dangerous presentation is the possibility of precancerous or even cancerous lesions if these warts persist for more than one to two years once they appear [5]. There are a number of HPV driven cancers that have been identified: cervical cancer, anal cancer, vulva cancer, vaginal cancer, penial cancer, and even oropharyngeal cancer (which includes cancer of the 
mouth, tongue, and throat). There has even been some correlation with the development of lung cancer due to contamination of HPV [6].

When discussing the possibility of HPV driven cancers, most conversations circle around the idea of HPV's correlation with cervical cancer. However, with the increase of screenings in developed countries, cervical cancer has been greatly reduced although there is now an increase of anal and oropharyngeal cancer. With the prevalence of gender driven HPV related cancers being reduced, it may be time for countries such as the United States to start focusing on prevention and education efforts for both males and females [7].

Healthcare professionals carry many duties within their scope of practice, but one specific responsibility is to make sure patients are educated and understand what it takes to remain healthy. One area that seems to be under represented is in the education of young people regarding the benefits of the HPV vaccine. This research study was completed for multiple purposes, but this paper will specifically focus on those findings related to the overall comprehension of college students regarding HPV and associated cancers.

\section{Methodology}

To assess allied health students' knowledge, attitudes, and behaviors regarding the HPV, a survey was developed with the assistance of subject experts. After multiple reviews, the final version of the survey consisted of 34 questions. This survey was distributed to students enrolled in a variety of healthcare related programs which includes dental hygiene, healthcare management, mortuary science and funeral services, physical therapist assistants, and radiologic sciences which is comprised of specializations in radiography, radiation therapy, CT/ MRI, and sonography. A total of 414 usable surveys were collected from $100 \%$ of the students the surveys were distributed to.

\section{Demographics}

The population of this study consisted of about $81 \%$ of the respondents being females and $19 \%$ were males. Two participants did not fill out this question on the survey. The ethnic background for each respondent is as follows; $81 \%$ white, 10\% African American, 5\% Hispanic or Latino, and about 6\% selected indicted a different ethnicity.

When breaking the respondents into their undergraduate level of study, about $35 \%$ were in their senior year, 32\% were in their junior year, $21 \%$ were in their sophomore year, and $11 \%$ were in their freshman year. The survey also tracked what program of study each respondent was from; about $36 \%$ were listed in the radiological sciences program, $22 \%$ were in the dental hygiene program, $14 \%$ were in the mortuary science and funeral service program, $14 \%$ were in the physical therapist assistant program, and $12 \%$ were in the healthcare management program. Two respondents did not fill out this question on the survey. 


\section{Key Findings}

\section{What Cancers Correlated with HPV?}

One area of the study specifically asked college students what their base knowledge was about HPV and how they had been educated about the virus. One area of this study specifically asked what college students know or have been educated about when it comes to HPV. More specifically, which cancers college students perceive to be directly associated with the HPV infection. The research findings revealed there is an astounding gap between what most healthcare professionals think and what most college students know.

It appears that most college students do not have even an elementary level understanding about HPV, even though most healthcare professionals consider this information to be basic common knowledge. When asked about the correlation of directly linked cancers to HPV, the majority of college students could not identify these specifically (see Table 1 for student responses).

When asked about cancers that are not directly linked to HPV, these same college students demonstrated they have not acquired the basic understanding of HPV or the causative links to cancer, even though most of them are studying to become a healthcare professional (see Table 2 for student responses).

To help determine when HPV information should be discussed as well as the most appropriate age to administer the HPV vaccine, students were asked about the age of their first sexual relationship (see Table 3 for student responses). This information is considered pertinent as sexual intercourse is a primary means of contracting the HPV. The HPV vaccine does not protect against a strain once it has been contracted [6].

Table 1. Proven HPV related cancers.

\begin{tabular}{cccc}
\hline & Yes & No & Unsure \\
\hline Cervical Cancer & $10.5 \%$ & $38 \%$ & $51.5 \%$ \\
Head and Neck Cancer & $3.2 \%$ & $45.6 \%$ & $51.2 \%$ \\
Lung Cancer & $35.8 \%$ & $16.5 \%$ & $47.7 \%$ \\
Penile Cancer & $38 \%$ & $16 \%$ & $46 \%$ \\
Anal Cancer & $8.3 \%$ & $42.70 \%$ & $49 \%$ \\
\hline
\end{tabular}

Table 2. Proven HPV unrelated cancers.

\begin{tabular}{cccc}
\hline & Yes & No & Unsure \\
\hline Breast Cancer & $71.6 \%$ & $2.9 \%$ & $25.5 \%$ \\
Prostate Cancer & $41.4 \%$ & $12.9 \%$ & $45.7 \%$ \\
Brain Cancer & $12.4 \%$ & $36.10 \%$ & $51.5 \%$ \\
Testicular Cancer & $5.6 \%$ & $71.6 \%$ & $22.8 \%$ \\
\hline
\end{tabular}


Table 3. Age of first sexual relationship.

\begin{tabular}{cc}
\hline Age Range & Percentage \\
\hline Under 10 years of Age & $0.24 \%$ \\
$10-15$ years of age & $25.12 \%$ \\
16 - 18 years of age & $50.97 \%$ \\
$19-21$ years of age & $14.49 \%$ \\
Over 21 years of age & $4.35 \%$ \\
Students not Responding & $4.83 \%$ \\
\hline
\end{tabular}

\section{Discussion}

Research shows that the majority of new HPV infections take place in people who are in their late teens to early twenties, yet this research demonstrates the majority of the college students surveyed, have no indication of what cancers HPV can induce [8]. One statistic conducted by the CDC states that $70 \%$ of cervical cancer cases are directly correlated to HPV infections, which indicates how important this topic should be for this specific population [5]. Yet, almost $89 \%$ of those surveyed either thought HPV did not correlate with cervical cancer or was unsure if there was an association with the disease at all. An even more alarming discovery from the research found $71 \%$ of the college students thought HPV was a causative agent for breast cancer, although there is no relationship between breast cancer and HPV. If the current research is any sign on how college students perceive HPV or their overall level of understanding of the disease, it is fairly obvious that education on this topic or even communicating prevention methods such as the HPV vaccines are not being well transferred. Especially, when considering the HPV vaccines are the most beneficial before sexual activity is initiated since once a strain of the infection is acquired the vaccine will not protect against that specific strain of the virus [6]. The current research showed that over $75 \%$ of the respondents had been sexually active between the ages of 10 to 18 (see Table 3). This indicates students should be educated about HPV long before they reach college age.

Cancer is considered one of the main three preventable diseases along with heart disease and diabetes that affect approximately 1.7 million Americans each year [9]. When specifically discussing HPV related cancers, there are vaccines that can reduce ones risk of developing these cancers. It was stated by the former Secretary of Health and Human Services, Tommy Thomson, that approximately $95 \%$ of the budgetary healthcare expenditure is spent on treating patients, while only $5 \%$ of the expenses were devoted toward prevention [9]. The price of Gardasil (one of the HPV vaccines) according to the CDC is about \$134 for a single dose, so after all three doses an individual would have about $\$ 400$ invested in the vaccine and even less if it is covered by their insurance [10]. When estimating the overall expense of HPV related disease due to infections and cancer precursors, the cost is estimated to be about $\$ 3.4$ billion nationwide and this does not take into account indirect costs such as quality of life and time lost from work 
due to sickness [6]. When considering the possible cost savings from the vaccination of HPV, it seems rational to assume that educating young people and their parents should be a priority, however, it seems this is not yet the case.

\section{Conclusion}

This research reveals that young people are not being educated about the risks of HPV or the cancers that it can cause once infected. HPV vaccination should not be considered or looked at as a parent giving permission to their child to have sexual intercourse, but rather as a deterrent to developing life-threatening disease such as cancer later in life. One study found that $46 \%$ of females had HPV diagnosed prior to vaginal intercourse, which indicates sexual intercourse is not the only method to contract the infection [11]. Being able to educate the public on the idea of vaccination against HPV infection should help reduce the overall illness induced by HPV, as well as reduce possible expense associated with the infection. It is estimated the United States annual spending on healthcare is close to $\$ 4$ trillion dollars a year and is projected to be about $\$ 5$ trillion by 2022 [12]. Simple preventive measures such as HPV vaccination could help reduce some of this expense and as a possible added benefit, save the lives of future generations as they become adults.

\section{References}

[1] Syrjänen, S. and Syrjänen, K. (2008) The History of Papillomavirus Research. Central European Journal of Public Health, 16, S7-S13.

[2] Fakhraei, F. and Haghshenas, M.R. (2013) Human Papillomaviruses and Cancer. Journal of Mazandaran University of Medical Sciences, 23, 457-480.

[3] Centers for Disease Control and Prevention (2015) Genital HPV Infection-Fact Sheet. http://www.cdc.gov/std/hpv/stdfact-hpv.htm

[4] Centers for Disease Control and Prevention (2004) Genital HPV Infection-Fact Sheet.

[5] Centers for Disease Control and Prevention (2012) Human Papillomavirus-Associated Cancers-United States, 2004-2008. American Journal of Transplantation, 12, 1945-1949. https://doi.org/10.1111/j.1600-6143.2012.04188.x

[6] Harper, D.M. (2005) Are We Closer to the Prevention of HPV-Related Diseases? Journal of Family Practice, 54, S10-S16.

[7] Kreimer, A.R. (2014) Prospects for Prevention of HPV-Driven Oropharynx Cancer. Oral Oncology, 50, 555-559. https://doi.org/10.1016/j.oraloncology.2013.06.007

[8] Centers for Disease Control and Prevention (2012) HPV Vaccine Information for Young Women.

http://www.cdc.gov/std/hpv/stdfact-hpv-vaccine-young-women.htm

[9] Dursi, M. (2008) Can Health Promotion Programs Effectively Reduce Health Care Costs, Increase Productivity and Retain Qualified Employees? University of Rhode Island.

[10] Centers for Disease Control and Prevention (2015) CDC Vaccine Price List. http://www.cdc.gov/vaccines/programs/vfc/awardees/vaccine-management/price-lis t/index.html

[11] Shew, M.L., Weaver, B., Tu, W., Tong, Y., Fortenberry, J.D. and Brown, D.R. (2013) 
High Frequency of Human Papillomavirus Detection in the Vagina before First Vaginal Intercourse among Females Enrolled in a Longitudinal Cohort Study. The Journal of Infectious Diseases, 207, 1012-1015. https://doi.org/10.1093/infdis/jis775

[12] Munro, D. (2014) Annual US Healthcare Spending Hits \$3.8 Trillion. http://www.forbes.com/sites/danmunro/2014/02/02/annual-u-s-healthcare-spendin g-hits-3-8-trillion/

Submit or recommend next manuscript to SCIRP and we will provide best service for you:

Accepting pre-submission inquiries through Email, Facebook, LinkedIn, Twitter, etc. A wide selection of journals (inclusive of 9 subjects, more than 200 journals)

Providing 24-hour high-quality service

User-friendly online submission system

Fair and swift peer-review system

Efficient typesetting and proofreading procedure

Display of the result of downloads and visits, as well as the number of cited articles Maximum dissemination of your research work

Submit your manuscript at: http://papersubmission.scirp.org/

Or contact abcr@scirp.org 